\title{
HUBUNGAN ANTARA POWER OTOT TUNGKAI, POWER OTOT LENGAN, DAN KOORDINASI MATA-TANGAN DENGAN KETERAMPILAN SMASH BOLA VOLI PADA SISWA PUTRA
} EKSTRAKURIKULER SD MUHAMMADIYAH 3 SURAKARTATAHUN 2020

\author{
Jasmani \\ Universitas Tunas Pembangunan Surakarta
}

\begin{abstract}
ABSTRAK
Tujuan dari penelitian ini adalah untuk mengetahui: (1) Hubungan antara Power otot tungkai denganKeterampilan Smash Pada Siswa Putra Ekstrakurikuler SD Muhammdiyah 3 Surakarta Tahun 2020 (2) Hubungan antara Power Otot Lengan Dengan Keterampilan Smash Pada Siswa Putra Ekstrakurikuler SD Muhammdiyah 3 Surakarta Tahun 2020 (3) Hubungan antara Koordinasi Mata Tangan Dengan Keterampilan Smash Pada Siswa Putra Ekstrakurikuler SD Muhammadiyah 3 Surakarta Tahun 2020 (4) Hubungan Antara Power Otot Tungkai, Power Otot Lengan, Dan Koordinasi Mata Tangan Dengan Keterampilan Smash Pada Siswa Putra Ekstrakurikuler SD Muhammdiyah 3 Surakarta Tahun 2020.

Sesuai dengan tujuan penelitian ini, maka penelitian ini menggunakan metode deskriptif dengan pendekatan studi korelasional. Penelitian ini dilaksanakan di Lapangan SD Muhammdiyah 3 Surakarta pada Siswa Putra Ekstrakurikuler SD Muhammdiyah 3 Surakarta Tahun 2020 dan penelitian ini dilaksanakan pada bulan Januari tahun 2020. Adapun jenis tes yang digunakan adalah: (1) Tes dan pengukuran power otot tungkai dengan vertical jumptest (Barry L Johnson, 1979: 201-4), (2) Tes dan pengukuran power otot lengan dengan two-hand medicine ball put (Ismaryati, 2011:64), (3) Tes dan pengukuran koordinasi mata tangan dengan tes memantulkan bola ketembok (Mulyono B, 1988: 78), (4) Tesketerampilan Smash dari Pusat Pengembangan Kualitas Jasmani, Departemen Pendidikan Nasional (2003: 16).

Berdasarkan analisis data dan pengujian hipotesis yang telah dilakukan, maka simpulan yang dapat diperoleh adalah: (1) Ada hubungan yang signifikan antara Power otot tungkai dengan Ketrampilan Smash, $\mathrm{r}_{\text {hitung }}=0.429>\mathrm{r}_{\text {tabel }} \%=0,361$. (2) Ada hubungan yang signifikan antara Power otot lengan dengan Ketrampilan Smash, $\mathrm{r}_{\text {hitung }}=0.410>\mathrm{r}_{\text {tabel }} 5 \%=0,361$. (3) Ada hubungan yang signifikan antara Koordinasi mata tangan dengan Ketrampilan Smash, $\mathrm{r}_{\text {hitung }}=0.400>\mathrm{r}_{\text {tabel }} \%=0,361$. (4) Ada hubungan yang signifikan antara Power otot tungkai, Power otot lengan dan Koordinasi mata tangan dengan Ketrampilan Smash, $\mathrm{R}_{\mathrm{y}(123)}^{2}$ sebesar $0.442>\mathrm{r}_{\text {tabel5 }} \%$ pada taraf signifikansi $5 \%$ sebesar 0.361 dan $\mathrm{F}_{0}$ sebesar6.8787 $>\mathrm{f}_{\text {tabel }}$ pada taraf signifikansi $5 \%$ sebesar 2,89.
\end{abstract}

Kata Kunci : Power otot tungkai, Power otot lengan, Koordinasi mata tangan, Ketrampilan Smash 


\section{PENDAHULUAN}

\section{A. Latar Belakang Masalah}

Salah satu olahraga yang merakyat di Indonesia adalah bolavoli.Dari penjuru tanah air mengenal semua permainan bolavoli.Tidak membutuhkan banyak biaya untuk melakukan permainan bolavoli ini. Cuma dengan sarana prasarana apa adanya dan kemampuan meloncat sudah bisa melakukan permainan ini.Untuk memperoleh kemampuan meloncat yang baik, maka perlumengkaji masalah faktor-faktor yang mempengaruhi kemampuan meloncat dalam upaya meningkatkan prestasi olahraga tersebut. Loncatan yang baik dapat dilakukan dengan maksimal jika melibatkan beberapa anggota gerak tubuh.Hal ini disebabkan bahwa rangkaian gerak meloncat yang baik tidak terlepas dari dukungan beberapa anggota badan.

Berbagai cabang olahraga yang memerlukan gerakan meloncat, dapat diamati adanya macam-macam bentuk gerakan yang tidak selalu sama. Ada yang menggunakan tumpuan dua kaki bersama-sama dan ada yang menggunakan tumpuan satu kaki, ada yang arah gerakannya cenderung ke depan dan ada yang cenderung ke atas, ada yang bertujuan meloncat sejauh-jauhnya dan ada yang bertujuan meloncat setinggi-tingginya.

Bolavoli merupakan salah satu cabang permainan dimana dalam permainannya gerakan meloncat sangat sering dilakukan. Gerakan meloncat merupakan gerakan yang dominan dari gerakan smash dan blok. Tanpa gerakan meloncat, smash dan blok tidak mungkin dapat dilakukan. Selain untuk smash dan blok, gerakan meloncat juga sering dilakukan pada saat memainkan bola dengan teknik passing atas. Gerakan smash dan blok dalam permainan bolavoli hanya bisa dilakukan dengan baik apabila pemain memiliki loncatan yang tinggi.

Tipe Permainan dalam permainan bolavoli secara umum dapat diklasifikasikan menjadi tiga macam yaitu: tipe menyerang, tipe mengumpan, dan tipe pemain bertahan. Tipe menyerang atau menyemes merupakan salah satu taktik yang sangat efektif untuk menyerang lawan dan mematikan bola, Tipe menyerang 
khususnya smash pada umumnya harus mempunyai loneatan yang tinggi, Namun dalam kenyatannya pemain yang kakinya kelihatan berotot tidak selalu memiliki loneatan yang tinggi.

Secara akal sehat dapat dikatakan bahwa untuk mampu meloncat tinggi diperlukan otot kaki yang kuat, namun dalam kenyataannya banyak dijumpai pemain bolavoli yang kakinya nampak berotot tetapi loncatannya tidak tinggi, tetapi sebaliknya ada pemain yang kakinya kurang berotot justru loncatannya tinggi. Di samping itu untuk dapat melakukan pukulan smash yang keras dan tajatn, secara akal sehat lengan yang kelihatan berotot memiliki pukulan yang keras dan tajam. Tetapi juga banyak dijumpai seorang pemain yang lengannya kelihatankurang berotot pukulan smash ygng dilakukan lebih keras dan tajam. Kenyataan tersebut di atas menimbulkan pertanyaan-pertanyaan yang perlu diteliti.

Untuk itu diperlukan pengkajian secara mendalam terhadap berbagai faktor yang dapat mempengaruhi smash dalam permainan bolavoli khususnya smash. Berdasarkan uraian di atas, pengkajian akan diarahkan pada pokok permasalahan sebagai berikut: (1) kajian dari segi koordinasi mata-tangan, (2) kajian dari segi power otot tungkai, (3) kajian dari segi power otot lengan. Dari ketiga kajian tersebut muncul berbagai masalah yang perlu diteliti mengenai seberapa besar sumbangan power otot tungkai, power otot lengan dan koordinasi mata-tangan dengan keterampilan smash dalam permainan bolavoli.

Keterampilan smash pemain putra ekstrakurikuler SD Muhammadiyah 3 Surakarta dinilai kurang baik dan hal ini salah satunya disebabkan oleh belum diketahuinya komponen-komponen kondisi fisik dan bagian tubuh yang mendukung terhadap keterampilan smash. Faktor kondisi fisik khususnya power otot tungkai, power otot lengan dan koordinasi mata-tangan yang mempengaruhi kemampuan smash harus dilatih dan dikembangkan sehingga nanti dapat menopang dalam melakukan smash permainan bolavoli. 


\section{B. LANDASAN TEORI}

\section{Permainan Bolavoli}

\section{a. Pengertian Permainan Bolavoli}

Bolavoli merupakan olahraga Permainan yang dimainkan oleh dua regu dimana masing-masing regu terdiri dan enam orang pemain, Lapangan Permainan yang digunakan berukuran 18 x 9 meter berbentuk empat persegi panjang, Lapangan tersebut dibagi menjadi dua bagian yang sama oleh sebuah garis tengah yang diatasnya dibentangkan net sebagai pembatas antara kedua regu yang bertanding. Maksud dan tujuan Permainan adalah menjatuhkan bola di lapangan lawan melewati di atas net dan mencegah lawan melakukan hal yang sama di daerah permainannya sendiri. Feri Kurniawan (2012 : 119) mengemukakan di dalam perkembangannya peraturan Permainan bolavoli selalu mengalami perubahan. Hal ini didasarkan pada beberapa pertimbangan agar permainan bolavoli lebih menarik dan berkualitas. Akan tetapi faktor yang mendasar yang harus dikuasai oleh setiap pemain agar trampil bermain bolavoli adalah penguasaan teknik dasar. Selain hal tersebut perlu memperhatikan prinsipprinsip bermain bolavoli, sehingga setiap tindakan yang dilakukan tidak bertentangan dengan peraturan yang berlaku dan menguntungkan regunya. Prinsip-prinsip bermain bolavoli menurut sebagai berikut:

1). Memvoli bola di udara melewati jaring/net agar dapat jatuh di dalam lapangan lawan untuk mencari kemenangan bermain.

2). Satu regu (enam pemain) paling banyak dapat memainkan bola di lapangan sendiri tiga kali, dengan peraturan setiap pemain tidak diperbolehkan memainkan bola di udara dua kali berturut-turut.

3). Mengingat pemain bolavoli atau regu terdiri enam pemain, jelaslah prinsip-prinsip kerjasama antar pemain mutlak diperlukan. Oleh karena itu setiap individu harus memiliki sifat toleransi, saling percaya kerjasama yang baik.

Jurnal Ilmiah SPIRIT, ISSN; 1411-8319 Vol. 20 No. 2 Tahun 2020 
4). Bermain bola harus mendatangkan kesenangan tiap-tiap individu yang melakukan.

Berdasarkan pendapat tersebut menunjukkan bahwa, prinsip-prinsip bermain bolavoli tersebut di atas merupakan hal-hal yang hams diperhatikan oleh setiap pemain agar kualitas permainan menjadi baik. Kerjasama merupakan tuntutan dalam permainan, oleh karena itu setiap pemain harus memiliki sifat toleransi saling percaya sehingga permainan menjadi baik.

\section{b. Teknik Dasar Permainan Bolavoli.}

Dalam permainan bolavoli terdiri dari bermacam-macam teknik dasar baik teknik tanpa bola dan teknik dengan bola, Teknik-teknik tersebut harus dikuasai oleh setiap pemain bolavoli.Kualitas suatu permainan dapat dikatakan baik jika pemainnya menguasai dan malakukan teknik-teknik dan taktik yang baik dan dilakukan pada saat yang tepat. Teknik merupakan suatu proses gerakan dan pembuktian dalam praktek dengan sebaik mungkin, sedangkan tektik merupakan siasat untuk memenangkan permainan atau pertandingan secara sportif. Dengan teknik dan taktik yang baik permainan lebih bermutu dan menarik untuk ditonton. Bagi tim yang memiliki teknikyang tinggi dan taktik yang cermat akan membuahkan kemenangan bagi timnya.

Dengan menguasai teknik dasar, maka setiap tindakan yang dilakukan lebih efektif dan efisien serta akan menguntungkan timnya. Menurut Soedarwo, Sunardi \& Agus Margono (1996 : 6-7) bahwa pentingnya penguasaan teknik dasar dalam permainan bolavoli selain dapat bermain bolavoli dengan baik juga mengingat hal-hal sebagai berikut:

1) Hukuman terhadap pelanggaran permainan yang hubungannya dengan kesalahan teknik.

2) Karena terpisahnya tempat antara regu ke satu dengan regu yang lain, sehingga tidak terjadi adanya sentuhan badan dari permainan lawan, maka pengawasan wasit terhadap kesalahan teknik ini lebih seksama.

Jurnal Ilmiah SPIRIT, ISSN; 1411-8319 Vol. 20 No. 2 Tahun 2020 
3) Banyaknya unsur-unsur yang menyebabkan terjadinya kesalahankesalahan teknik ini antara lain membawa bola, mengangkat bola, serta pukulan rangkap.

4) Permainan bolavoli adalah, waktu untuk memainkan bola sangat sempurna sehingga akan memungkinkan timbulnya kesalahankesalahan teknik yang lebih besar.

5) Penguasaan taktik-taktik yang tinggi hanya dimungkinkan kalau penguasaan teknik dasar yang tinggi, dalam bolavoli ini cukup sempurna,

Berdasarkan pendapat di atas menunjukkan bahwa teknik dasar permainan bolavoli terdiri atas empat unsur pokok yaitu passing, smash, service dan block.Keempat teknik dasar tersebut harus dikuasai oleh setiap pemain, sehingga permainan menjadi kompak. Tanpa menguasai teknik dasar, tidak dapat bermain bolavoli dengan baik serta kerjasama dalam satu tim tidak dilakukan dengan baik.

\section{Smash}

\section{a. Pengertian Smash}

Di dalam permainan bolavoli, tidak dapat terlepas dari teknik smash, yaitu teknik penyerangan dengan berusaha mematikan permainan lawan dengan suatu pukulan yang keras dan terarah.

Menurut Sudarwo, Sunardi, dan Agus Margono (1996 : 13) "Gerakan smash adalah gerakan seorang pemain untuk berusaha mengadakan pukulan yang keras dan terarah sehingga sukar dikembalikan oleh lawan," Adapun proses di dalam melakukan smash dapat dibagi dalam saat-saat sebagai berikut:

1) Saat awalan

2) Saat tolakan

3) Saat pukulan bola di atas jaring

4) Saat mendarat di tanah

Dari keempat macam proses tersebut dilakukan secara bersama dan merupakan suatu kesatuan gerakan yang disebut gerakan smash. Di dalam 
permainan bolavoli dikenal berbagai macam smash. Menurut Soedarwo (1994 : 15), Smash dibagi menjadi 3 macam :

1) Normal smash

2) Semi smash

3) Push smash

Di dalam penelitian ini pembahasan dibatasi pasa smash dan dipersempit lagi pada smash.Untuk dapat melakukan smash, harus diperhatikan kapan smasher harus memukul bola di atas jaring. Pengambilan awalan ialah pada saat bola lepas dari tangan set-uper dan smasher segera mengontrolnya.Apabila jarak bola sejangkauan lengan pemukul, maka segera smasher meloncat ke atas dan meraih bola di atas jaring dengan suatu pukulan, dengan secepat-cepatnya dan setinggi-tingginya di atas jaring.

Keberhasilan smash juga sangat tergantung kepada sempurna atau tidaknya set-uper di dalam memberikan umpan. Agar penyajian dapat berhasil untuk melakukan smash, maka harus diperhatikan hal-hal sebagai berikut:

1) Lambungan bola harus cukup tinggi, yaitu lebih dari $3 \mathrm{~m}$ dan bola dalam keadaan tenang.

2) Bola selama menempuh lintasannya berjalan antara $20 \mathrm{~cm}$ sampai $50 \mathrm{~cm}$ jauhnya dari jaring.

3) Jarak jatuhnya bola berada di sekitar daerah yang letaknya sejauh setengah dari jarak yang diukur dari tempat set-uper berdiri sampai kepada titik proyeksi dari tempat permulaan smasher mengambil awalan.

Jurnal Ilmiah SPIRIT, ISSN; 1411-8319 Vol. 20 No. 2 Tahun 2020 


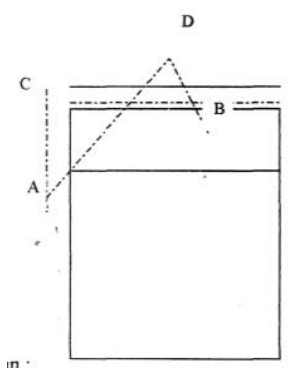

Gambar 1.

Daerah Jatuhnya Sasaran Umpan (Sunardi dan Deddy,2015 : 40)

Keterangan :

A: Tempat awalan smasher.

B : Tempat set-uper.

$\mathrm{C}$ : Proyeksi titik awalan smasher ke garis tengah lapangan.

D : Daerah jatuhnya umpan sejauh setengah jarak sampai B

Contoh urutan gerakan dalam melakukan smash. 1

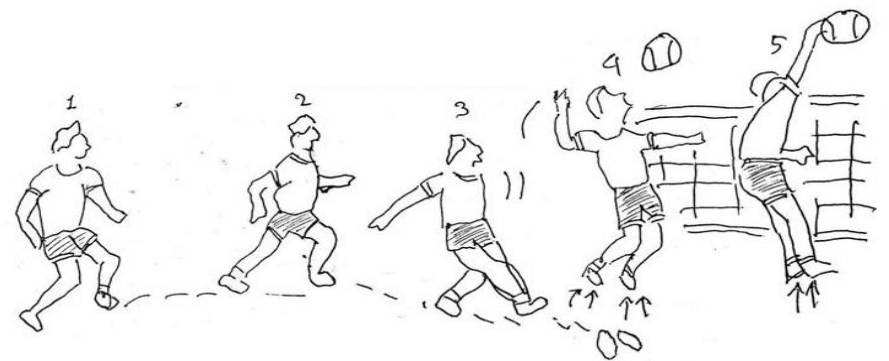

Gambar 2. Gambar Urutan Gerakan-smash

(Soedarwo, $1994: 41$ )

Keterangan gambar:

1. Satu sampai tiga langkah ancang-ancang,

2. Langkah lebar dan datar.

3. Kedua lengan diayun ke belakang.

4. Kedua kaki dihentakkan bersusulan, lalu meloncat, lengan yang akan memukul mulai terayun ke depan, punggung memegang ke belakang. 
5. Bola dipukul dengan lengan terjulur, tangan terbuka dan menaungi bola, pergelangan tangan hams longgar.

6. Mendarat dengan kedua kaki bersama-sama dan ngepir.

\section{Power Otot Tungkai}

\section{a. Power}

Setiap beraktifitas atau melakukan kegiatan olahraga otot merupakan komponen tubuh yangdominan dan tidak dapat dipisahkan. Semua gerakan yang dilakukan oleh manusia karena adanya otot, tulang, persendian, ligamen serta tendon, sehingga gerakan dapat terjadi melalui gerakan tarikan otot serta jumlah serabut otot yang diaktifkan. Berkaitan dengan power, Harsono (1988:200) menyatakan bahwa "Power adalah kemampuan otot untuk mengerahkan kekuatan maksimal dalam waktuyang sangat cepat”. Menurut Suharno HP (1993:59), yang menyatakan bahwa "Power adalah kemampuan otot pemain untuk mengatasi tahanan beban dengan kekuatan dan kecepatan maksimal dalam satu gerak yang utuh”.

Berdasarkan batasan-batasan power diatas dapat disimpulkan bahwapower adalah kemampuan untuk mengerahkan kekuatan dan kecepatan otot dalam waktu yang relatif singkat. Power merupakan perpaduan dua unsur komponen kondisi fisik yaitu kekuatan dan kecepatan dalam hal ini kekuatan dan kecepatan otot. Kualitas power akan tercermin dari unsur kekuatan dan kecepatan otot yang dalam pelaksanaannya dilakukan dengan eksplosif dalam waktu yang sesingkat mungkin.

\section{b. Macam-Macam Power}

Menurut Bompa (1999:385), power dibedakan dalam dua bentuk yaitu: power asiklik dan siklik. Perbedaan jenis power ini dilihat dari segi kesesuaian jenis latihan atau keterampilan gerak yang dilakukan. Dalam kegiatan olahraga power asiklik dan siklik dapat dikenali dari peranannya pada suatu cabang olahraga. Cabang-cabang olahraga yang memerlukan 
power asiklik secara dominan adalah melempar, menolak, melompat dan unsur-unsur gerakan pada senam, beladiri, anggar, loncat indah dan olahraga permainan seperti bolavoli dan sepakbola. Sedangkan cabang-cabang olahraga yang menggunakan power siklik adalah: lari, dayung, renang, bersepeda dan jenis olahraga yang memerlukan kecepatan dalam pelaksanaannya.

\section{c. Otot Tungkai}

Tungkai terdiri dari tungkai atas dan tungkai bawah. Tungkai atas terbagimenjadi: pangkal paha sampai lutut, sedangkan tungkai bawah terbagi atas lututsampai dengan kaki (Soedarminto, 1991: 60-61). Tulang tungkai atau tulanganggota gerak bawah terdiri dari: (1) Tulang pangkal paha, (2) Tulang paha, (3)Tulang kering, (4) Tulang betis, (5) Tulang tempurung lutut, (6) Tulang pangkal kaki, (7) Tulang telapak kaki, dan (8) Tulang ruas jari kaki (Syaifudin, 1997: 31).

1) Otot tungkai atas

Otot tungkai atas meliputi: (1) M. Abduktor Maldanus Internal, (2) M. Abduktor Brevis Medial, (3) M. Abduktor Lonngus Eksternal, (4) M. Rektus Rektus Femoris, (5) M. VastusLateralis Eksternal, (6) M. Vastus Medialis Internal, (7) M. Vastus Intermedial, M.Bicepsfemoris, (9) M. Semi Membranosus, (10) M. Semi Tendinosus, dan (11) M.Sartorius (Syaifudin, 1997:56).

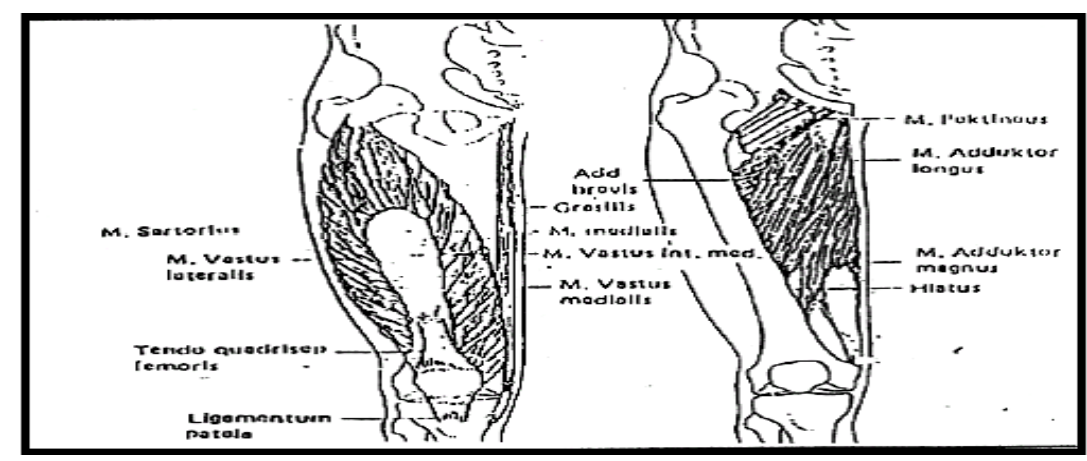

Gambar 3. Otot Tungkai Atas (Syaifudin, 1997: 46) 
2) Otot tungkai bawah

Otot-otot tungkai bawah terdiri dari: (1) M. Tibialis Anterior, (2) M.Ekstensor Talangus Longus, dan (6) M. Tibialis Posterior, (7) M. Gastroknemus(Syaifudin, 1997: 58).

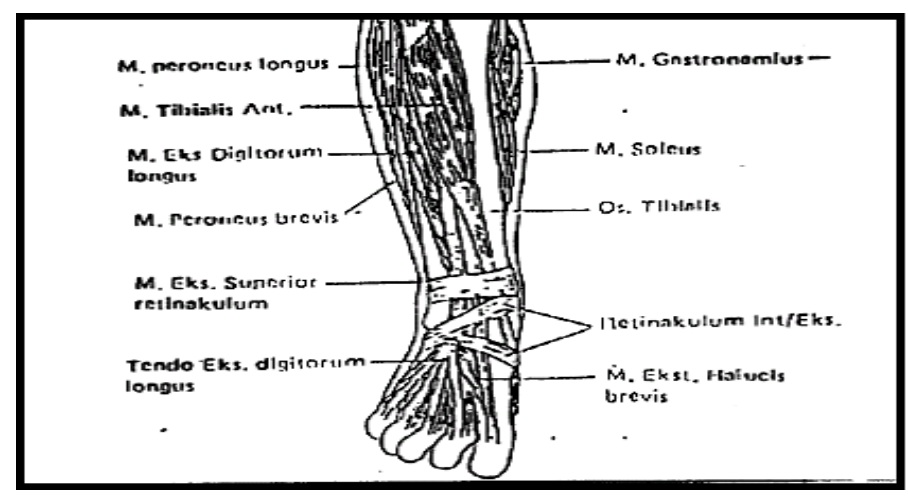

Gambar 4. Otot Tungkai Bawah (Syaifudin, 1997: 47)

\section{d. Peranan Power Otot Tungkai dengan Keterampilan Smash}

Power otot tungkai memiliki peranan yang sangat penting hampir pada semua cabang olahraga, baik olahraga individu maupun beregu power otot tungkai mempunyaikontribusi yang sangat besar terhadap tercapainya sebuah prestasi. Power otot tungkai merupakan dasar untuk mencapai keterampilan yang tinggi dalam melakukan keterampilan smash. Keterampilan smashterdapat gabungan beberapa gerakan yang harus dilakukan secara terpadu dan selaras. Untuk melakukan teknik keterampilan smashsecara sempurna diperlukan kemampuan power otot tungkai yang baik. Power otot tungkai adalah salah satu unsur yang penting untuk keterampilan gerak motorik. Pemain dengan power yang baik bukan hanya mampu melakukan suatu keterampilan secara sempurna, akan tetapi juga mudah dan cepat dapat melakukan keterampilan yang masih baru baginya. Disamping itu juga dapat mengubah secara cepat dari pola gerak yang satu ke pola gerak yang lain, sehingga gerakannya menjadi efektif dan efisien. 
Besarnya power otot tungkai yang diperlukan pada masing-masing cabang tentunya berbeda-beda, tergantung seberapa besar keterlibatan power otot tungkai dalam cabang olahraga tersebut.Meningkatnya power otot tungkaiakan menyebabkan koordinasi kerja neuromuskuler menjadi lebih baik. Pada keterampilan smash, keadaan power otot tungkai dalam hal ini sangat tergantung pada kemampuan seorang pemain untuk memperhitungkan dan membina kondisi fisiknya dengan cara yang kuat dan cepat melalui gerakan keterampilan smash

\section{Power Otot Lengan}

\section{a. Pengertian Power}

Dua unsur dalam power yaitu: 1) Kekuatan otot, 2) Kecepatan kontraksi otot dalam menggerakkan tenaga maksimal untuk mangatasi tahanan. Suharno HP (1978: 33) mendefinisikannya sebagai berikut: "Daya ledak (power) adalah kemampuan otot atau segerombolan otot untuk mengatasi tahanan beban dengan kecepatan tinggi dalam suatu gerakan yang utuh". Dari pengertian ini daya ledak menunjukkan kemampuan seseorang untuk melakukan suatu gerakan secara mendadak yang dihasilkan oleh kerja otot seeara keseluruhan, dalam hai ini adalah kerja otot lengan. M. Sajoto (1995: 8) juga berpendapat bahwa "daya otot atau muscular power adalah kemampuan seseotang untuk mempergunakan kekuatan maksimal yang dikerahkan dalam wakta sependek-pendeknya".

Dalam hal ini dapat dinyatakan power adalah hasil kali antara kecepatan dan kekuatan. Power merupakan salah satu dasar atau komponen yang penting guna peningkatan kondisi fisik. Akan tetapi yang pasti adalah atlet harus cukup kuat melakukan tugas olahraganya secara efisien, tanpa mengalami kelelahan yang berlebihan saat latihan power dalam praktek olahraga, seperti lompat, loncat, lari dan sebagainya. Power sangat bermanfaat bagi atlet dalam mencapai prestasi maksimal.Agar hasihiya efektif, latihan harus dilakukan sedemikian rupa sehingga atlet harus 
mengeluarkan tenaga maksimal atau hampir maksimal untuk menahan beban tersebut.Beban tersebut harus sedikit demi sedikit ditambah agar perkembangan otot terjamin. Oleh karena itu, latihan harus menerapkan proses progresif.

\section{b. Metode Latihan Pengembangan Power}

Dalam usaha peningkatan power otot lengan tidak cukup hanya dengan membuat program latihan saja, tetapi juga harus memiliki metode yang efekfif dan efisien. Suharno HP (1993: 1) menyatakan bahwa "metode latihan dapat efektif dan efisian tergantung beberapa faktor antara lain: pelatih, atlet, alat fasilitas, tujuan latihan, waktu, dan lingkungan berlatih".Metode latihan yang digunakan untuk peningkatan power seorang atlet ada bermacam-macam, seperti metode weight training, interval, dan plyometric. Dalam penelitian ini penulis akan memilih cara peningkatan power otot lengan dengan metode interval training. Adapun yang dimaksud dengan interval training adalah suatu sistem yang diselingi interval-interval yang merupakan masa-masa istirahat.Latihan-istirahat-latihan-istirahat dan seterusnya. Ada beberapa faktor yang harus dipenuhi dalam menyusun interval training yaitu:

1. Lamanya latihan,

2. Beban/intensitas training,

3. Ulangan/repetisi latihan,

4. Masa istirahat/recovery interval setelah setiap repetisi latihan.

\section{Koordinasi Mata Tangan}

\section{a. Pengertian Koordinasi}

Koordinasi adalah kemampuan mengendalikan bagian-bagian tubuh yang terlibat dalam suatu pola gerak komplek dan memadukan bagianbagian ini ke dalam suatu gerak timggal yang harmonis dan berhasil mencapai tujuan. Menurut Suharno HP (1993:61) "koordinasi adalah 
kemampuan seseorang merangkaikan beberapa unsur gerak menjadi satu gerakan yang selaras". Adapun menurut Iskandar Z. Adisaputra, dkk (1999:10), yang dimaksud dengan koordinasi adalah "kemampuan untuk melakukan gerakan dengan tepat dan efisien.Koordinasi menyatukan hubungan harmonis berbagai faktor yang terjadi pada suatu gerakan", Selanjutnya M. Sajoto (1995:9) berpendapat bahwa "koordinasi adalah kemampuan seseorang dalam mengintegrasikan bermacam-macam gerakan yang berbeda ke dalam pola gerakan yang tunggal secara efektif.

Dari uraian tersebut dapat disimpulkan bahwa koordinasi merupakan kemampuan seseorang untuk merangkaikan atau mengintegrasikan gerakan ke dalam satu pola yang selaras, efisien dan efektif, sesuai dengan tujuan.Berlandaskan pengertian tersebut maka koordinasi mata-tangan dapat diartikan sebagai kemampuan seseorang dalam mengintegrasikan antara gerakan mata (pandangan) dengan gerakan tangan secara efektif.

\section{HASIL PENELITIAN \& PEMBAHASAN}

\section{Hubungan Antara Power otot tungkai dengan Ketrampilan Smash}

Dari hasil analisis korelasi pada dataPower otot tungkai dengan Ketrampilan Smash, diperoleh nilai r sebesar 0.429, dimana nilai tersebut lebih besar dari nilai $r_{\text {tabel }}$ pada taraf signifikansi 5\% yaitu 0,361. Karena nilai $r_{\text {hitung }}>$ $\mathrm{r}_{\text {tabel}}$, maka nilai korelasi signifikan.Hal ini berarti bahwaperubahan variansi Ketrampilan Smash dipengaruhi oleh komponen variansi Power otot tungkai.

\section{Hubungan Antara Power otot lengan dengan Ketrampilan Smash}

Berdasarkan hasil analisis yang telah dilakukan terhadap data Power otot lengan terhadap Ketrampilan Smash, diperoleh nilai r sebesar 0.410, dimana nilai tersebut lebih besar dari nilai $r_{\text {tabel }}$ pada taraf signifikansi $5 \%$ yaitu 0,361. Karenanilai $r_{\text {hitung }}>r_{\text {tabel}}$, maka nilai korelasi signifikan.Hal ini berarti bahwa variansi unsur Power otot lengan berpengaruh terhadap peningkatan variansi Ketrampilan Smash.

Jurnal Ilmiah SPIRIT, ISSN; 1411-8319 Vol. 20 No. 2 Tahun 2020 


\section{Hubungan Antara Koordinasi mata tangan dengan Ketrampilan Smash}

Berdasarkan hasil analisis yang telah dilakukan terhadap data Koordinasi mata tanganterhadap Passing atas, diperoleh nilai $\mathrm{r}$ sebesar 0.400 , dimana nilai tersebut lebih besar dari nilai $r_{\text {tabel }}$ pada taraf signifikansi $5 \%$ yaitu 0,361. Karenanilai $r_{\text {hitung }}>r_{\text {tabel}}$, maka nilai korelasi signifikan.Dengan demikian dapat disimpulkan bahwa Koordinasi mata tangan memiliki hubungan yang signifikan terhadap Ketrampilan Smash.

\section{Hubungan Power otot tungkai, Power otot lengandan Koordinasi mata} tangan dengan Ketrampilan Smash

Pada Hipotesis dinyatakan bahwa hubungan antara Power otot tungkai, Power otot lengandan Koordinasi mata tangan dengan Ketrampilan Smas] ketahui $\mathrm{R}_{\mathrm{y}(123)}^{2}=0.442$ sedangkan $\mathrm{r}_{\text {tabel }}$ pada taraf signifikasi 0,05 dan $\mathrm{n}=3 \mathrm{v}$ u

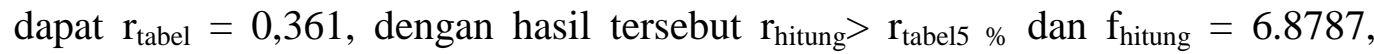
sedangkan $\mathrm{f}_{\text {tabel5\% }}$ dengan db 3:26 $=2,89$, ini berarti $\mathrm{F}_{0}>\mathrm{F}_{\text {tabel5\% }}$ Maka hipotesis di terima.

\section{SIMPULAN, IMPLIKASI DAN SARAN}

\section{Simpulan}

Berdasarkan hasil penelitian dan hasil analisis regresi dan korelasi product moment yang telah dilakukan dapat diperoleh simpulan sebagai berikut:

a. Ada hubungan yang signifikanantara Power otot tungkai dengan Ketrampilan Smash, $r_{\text {hitung }}=0.429>r_{\text {tabel } 5 \%}=0,361$.

b. Ada hubungan yang signifikan antara Power otot lengandengan Ketrampilan Smash, rhitung $=0.410>$ rtabel $5 \%=0,361$.

c. Ada hubungan yang signifikan antara Koordinasi mata tangan dengan Ketrampilan Smash termasuk data inversi karena lebih kecil dari r tabel, rhitung $=0.400<\operatorname{rtabel} 5 \%=0,361$.

d. Ada hubungan yang signifikan antara Power otot tungkai, Power otot lengandan Koordinasi mata tangan dengan Ketrampilan Smash, $\mathrm{R}_{\mathrm{y}(123)}$ 


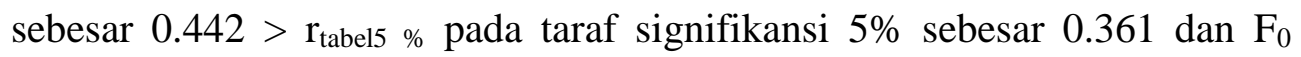
sebesar $6.8787>\mathrm{f}_{\text {tabel }}$ pada taraf signifikansi $5 \%$ sebesar 2,89 .

\section{Saran}

Sehubungan dengan simpulan yang telah diambil, maka kepada guru olahraga, khususnya di Sekolahan, disarankan agar:

a. Dalam upaya untuk meningkatkan Ketrampilan Smash hendaknya memberikan latihan Power otot tungkai, Power otot lengan dan Koordinasi mata tangan.

b. Latihan fisik yang diberikan harus proporsional. Besarnya porsi latihan untuk tiap unsur Power otot tungkai, Power otot lengan dan Koordinasi mata tangan disesuaikan dengan besarnya nilai hubungan tiap variabel terhadap Ketrampilan Smash.

\section{DAFTAR PUSTAKA}

Amung Ma'mun dan Toto Subroto. 2001. Pendekatan Keterampilan Taktis.dalam Pembelajaran Bola Voli. Jakarta: Departemen Pendidikan Nasional.

Barry, Johnson L and Jack K. Nelson. 1986.Practical Measurements for Evaluation in Physical education.New Delhi: Surjeet Publications, (3rd ed.), Indian reprint.

Bompa, T. O. 1999. Power Training For Sport: Plyometrics For Maximum Power Developmwnt. Ontario: Mosaic Press.

Depdiknas. 2003. Petunjuk Tes Keterampilan Bolavoli. Jakarta: Pusat Kesegaran Jasmani dan Rekreasi Departemen Pendidikan Nasional.

Feri Kurniawan. 2012. Buku Pintar Pengetahuan Olahraga. Penerbit: Laskar Aksara. Jakarta Timur.

Harsono. 1988. Aspek-aspek Psikologi Dalam Coaching. Jakarta: CV. Tambak Kusuma Jakarta.

Iskandar Z. Adi Sapoetra. 1999. Panduan Teknis Dan Latihan Kesegaran Jasmani. Jakarta: Pusat Pengkajian Dan Pengembangan Iptek Olahraga. Kantor Menteri Negara Pemuda Dan Olahraga. 
Ismaryati. 2008. Tes dan Pengukuran Olahraga. Cetakan 2. Surakarta: LPP UNS dan UNS Press.

Mulyono Biyakto Atmojo. 1988. Tes dan Pengukuran dalam Pendidikan Jasmani/Olahraga. Surakarta: LPP UNS dan UNS Press.

M. Sajoto. 1995. Peningkatan \& Pembinaan Kekuatan Kondisi Fisik Dalam Olahraga. Semarang: Dahara Prize.

Pusat Pengembangan Kualitas Jasmani. 2003. Petunjuk Tes Keterampilan BolavoliUsia 13-18 Tahun. Jakarta: Departemen Pendidikan Nasional.

Soedarminto. 1991. Kinesiologi. Jakarta : Depdikbud.

Sudarwo, Sunardi, dan Agus Margono, 1996. Teori dan Praktik Bola Voli Dasar. Surakarta: UNS Press

Suharno HP. 1985. Ilmu Kepelatihan Olahraga. Yogyakarta: IKIP Yogyakarta Press

Sunardi dan Deddy Whinata Kardiyanto. 2015. Bola Voli. Surakarta: UNS Press.

Suharto. 1999. Tes Kesegaran Jasmani Indonesia. Jakarta: Pusat Kesegaran Jasmani dan Rekreasi. 